\title{
Analysis of risk factors of low cardiac output syndrome after congenital heart disease operation: what can we do
}

\author{
Bangrong Song, Haiming Dang and Ran Dong*
}

\begin{abstract}
Background: It's necessary to analyze the related risk factors and complications of low cardiac output syndrome $(L C O S)$ after operation in children with congenital heart disease (CHD), to elucidate the management strategy of LCOS.

Methods: CHD children admitted to the department of cardiology in our hospital from January 15, 2019 to October 31, 2020 were included. The personal and clinical data of CHD children with LCOS and without LCOS were collected and compared. Logistic regression analyses were conducted to identify the risk factors of postoperative LCOS. Besides, the complication and mortality of LCOS and no LCOS patients were compared.

Results: A total of $283 \mathrm{CHD}$ patients were included, the incidence of postoperative LCOS in CHD patients was $12.37 \%$. There were significant differences in the age, preoperative oxygen saturation, two-way ventricular shunt, duration of CPB and postoperative residual shunt between two groups (all $p<0.05$ ). Logistic regression analyses indicated that age $\leq 4 \mathrm{y}(\mathrm{OR} 2.426,95 \% \mathrm{Cl} 1.044 \sim 4.149)$, preoperative oxygen saturation $\leq 93 \%(\mathrm{OR} 2.175,95 \% \mathrm{Cl} 1.182 \sim$ 5.033), two-way ventricular shunt (OR3.994, 95\%Cl1.247 6.797), duration of CPB $\geq 60 \min (\mathrm{OR} 2.172,95 \% \mathrm{Cl} 1.002$ 4.309), postoperative residual shunt (OR1.487, 95\%Cl1.093 2.383) were the independent risk factors of LCOS in patients with CHD (all $p<0.05$ ). There were significant differences in the acute liver injury, acute kidney injury, pulmonary infection, tracheotomy, duration of mechanical ventilation, length of ICU stay and mortality (all $p<0.05$ ), no significant difference in the $24 \mathrm{~h}$ drainage was found $(p=0.095)$.

Conclusion: $L C O S$ after CHD is common, more attentions should be paid to those patients with age $\leq 4 y$, preoperative oxygen saturation $\leq 93 \%$, two-way ventricular shunt, duration of CPB $\geq 60$ min, postoperative residual shunt to improve the prognosis of CHD patients.
\end{abstract}

Keywords: Low cardiac output syndrome, Congenital heart disease, Cardiology, Pediatric, Surgery, Treatment, Care

\section{Background}

Congenital heart disease (CHD) is kind of heart disease caused by abnormal development of the heart and blood vessels in the fetus, and it is very common in the clinical pediatric cardiology [1]. Because of its inability to heal itself, relevant surgery treatment is needed for patients

\footnotetext{
* Correspondence: randong03@yeah.net

Department of Cardiac Surgery, Beijing Anzhen Hospital, Capital Medical University, No.2 Anzhen Road, Chaoyang, Beijing 100029, China
}

with CHD [2]. The early diagnosis and treatment of $\mathrm{CHD}$ is essential to the prognosis of patients. Correction of congenital malformations by cardiopulmonary bypass (CPB) under direct vision is the main surgical method for the treatment of CHD [3]. Low cardiac output syndrome (LCOS) is a common serious complication after the operation of CHD, the incidence of LOCS after operation varies from 9.08 to $21.25 \%$, and it is also the major cause of death of children after operation $[4,5]$.

(c) The Author(s). 2021 Open Access This article is licensed under a Creative Commons Attribution 4.0 International License, which permits use, sharing, adaptation, distribution and reproduction in any medium or format, as long as you give appropriate credit to the original author(s) and the source, provide a link to the Creative Commons licence, and indicate if changes were made. The images or other third party material in this article are included in the article's Creative Commons licence, unless indicated otherwise in a credit line to the material. If material is not included in the article's Creative Commons licence and your intended use is not permitted by statutory regulation or exceeds the permitted use, you will need to obtain permission directly from the copyright holder. To view a copy of this licence, visit http://creativecommons.org/licenses/by/4.0/ The Creative Commons Public Domain Dedication waiver (http://creativecommons.org/publicdomain/zero/1.0/) applies to the data made available in this article, unless otherwise stated in a credit line to the data. 
Therefore, the prevention of postoperative LCOS in CHD patients is of great significance to improve the prognosis of patients.

In recent years, with the improvement of medical materials and surgical techniques, the incidence of postoperative LCOS has been reduced [6, 7]. However, the occurrence of postoperative LCOS is related to higher mortality and poor prognosis [8]. Therefore, reducing the incidence of postoperative LCOS in children with CHD is important to the prognosis of CHD patients. At present, there are few studies on the risk factors of LCOS in children after CHD. In this present study, we aimed to analyze the clinical data of children with CHD, to identify the risk factors of LCOS in children after $\mathrm{CHD}$ and their influence on the clinical prognosis of CHD patients, thereby providing reliable evidences to the clinical LCOS preventions and CHD managements.

\section{Methods}

\section{Ethics approval}

In this study, all methods were performed in comply with the relevant guidelines and regulations. Our study had been approved by the ethics committee of our hospital (XC201811029a), and written informed consents had been obtained from the relatives or guardians of the included CHD children.

\section{Patients}

We selected children with CHD who were admitted to the department of cardiology in our hospital from January 15,2019 to October 31, 2020 as the research population. The inclusion criteria of this study were: (1)The diagnosis of CHD in all children was confirmed by cardiac color Doppler ultrasound. (2)All children underwent intracardiac malformation correction surgery under $\mathrm{CPB}$ in our hospital. (3)The family members of the patients were informed and agreed to participate in this study. The exclusion criteria of this study were: (1)children who underwent emergency surgery; (2)age $>14$ years old; (3)children who received cardiac interventional therapy; (4) Patients with missing clinical data.

\section{The diagnosis of LCOS}

The diagnosis of LCOS was made if patients met more than two of following diagnostic criteria $[9,10]$ : (1) Heart index $<2 \mathrm{~L} \cdot \mathrm{min}^{-1} \cdot \mathrm{m}^{-2}$; (2) Systolic blood pressure $<90$ $\mathrm{mmHg}$ or systolic blood pressure decreased by more than 20\% compared with preoperative blood pressure; (3) Central venous pressure $>15 \mathrm{cmH}_{2} \mathrm{O}$; (4) The difference between the central temperature and the peripheral temperature $>5{ }^{\circ} \mathrm{C}$, and the limbs were cold; (5) Urine volume $<0.5 \mathrm{ml} \cdot \mathrm{kg}^{-1} \cdot \mathrm{h}^{-1}$ for more than $2 \mathrm{~h}$. According to whether LCOS occurred after operation, the patients were divided into LCOS group and no LCOS group.

\section{Data collections}

Two authors collected and recorded the preoperative, intraoperative and postoperative clinical data with unified form, including the diagnosis of CHD, gender, age(y), preoperative oxygen saturation(\%), inner diameter of left atrium $(\mathrm{mm})$, end diastolic diameter of left ventricle $(\mathrm{mm})$, end systolic diameter of left ventricular $(\mathrm{mm})$, left ventricular ejection fraction (\%), inner diameter of pulmonary artery $(\mathrm{mm})$, atrial and ventricular shunt, preoperative laboratory examination (white blood cell count, platelet count, red blood cell count, creatinine, alanine aminotransferase, aspartate aminotransferase), duration of surgery (min),duration of CPB (min), infusion of red blood cell suspension and postoperative residual shunt. The related variables of the two groups of children's risk factors were statistically compared, and risk factors were screened.

\section{Statistical processing}

All data in this study are statistically analyzed using SPSS 23.0 software. Measurement data were expressed as mean \pm standard deviation, and comparisons between groups were conducted by $\mathrm{t}$ test. Count data were expressed as the number of cases and percentages, and comparisons between groups were conducted by chi-square test. We performed multivariate logistic regression analysis on variables with significant statistical significance in univariate analysis between groups to explore the risk factors that affected children with LCOS after CHD surgery. In this study, the difference was statistically significant if $P<0.05$.

\section{Results}

Patients

A total of 283 CHD patients were included, of whom 35 patients had LCOS after surgery, the incidence of postoperative LCOS in CHD patients was $12.37 \%$. The type distributions of CHD were presented in Table 1. As indicated in Table 2, there were significant differences in the age, preoperative oxygen saturation, two-way ventricular shunt, duration of CPB and postoperative residual shunt (all $p<0.05$ ), and there were no significant differences in the gender, inner diameter of left atrium, end diastolic diameter of left ventricle, end systolic diameter of left ventricular, left ventricular ejection fraction, inner diameter of pulmonary artery, atrial shunt, white blood cell count, platelet count, red blood cell count, creatinine, alanine aminotransferase, aspartate aminotransferase, duration of surgery and infusion of red blood cell suspension (all $p>0.05$ ).

\section{Logistic regression analysis}

The variable assignments of multivariate logistic regression were presented in Table 3. As Table 4 showed, logistic regression results indicated that age $\leq 4 y(\mathrm{OR} 2.426$, 
Table 1 The types distribution of CHD

\begin{tabular}{|c|c|c|c|c|}
\hline Type of CHD & $\operatorname{LCOS}$ group $(n=35)$ & No LCOS group $(n=248)$ & $x^{2}$ & $P$ \\
\hline Ventricular septal defect & $14(40 \%)$ & $103(\%)$ & 1.297 & 0.084 \\
\hline Atrial septal defect & $8(22.85 \%)$ & $52(20.97 \%)$ & 1.102 & 0.087 \\
\hline Pulmonary artery stenosis & $4(11.43 \%)$ & $29(11.69 \%)$ & 1.177 & 0.104 \\
\hline Tetralogy of Fallot & $7(20 \%)$ & $44(17.74 \%)$ & 1.015 & 0.118 \\
\hline Right ventricular double outlet & $1(2.86 \%)$ & $11(4.44 \%)$ & 1.272 & 0.123 \\
\hline Pulmonary vein ectopic drainage & $1(2.86 \%)$ & $9(3.63 \%)$ & 1.136 & 0.096 \\
\hline
\end{tabular}

95\%CI1.044 4.149), preoperative oxygen saturation $\leq$ 93\%(OR2.175, 95\%CI1.182 5.033), two-way ventricular shunt (OR3.994, 95\%CI1.247 6.797), duration of $\mathrm{CPB} \geq 60$ $\min (\mathrm{OR} 2.172$, 95\%CI1.002 4.309), postoperative residual shunt (OR1.487, 95\%CI1.093 2.383) were the independent risk factors of LCOS in patients with CHD (all $p<0.05$ ).

\section{The postoperative complications and prognosis} comparison

As presented in Table 5, there were significant differences in the acute liver injury, acute kidney injury, pulmonary infection, tracheotomy, duration of mechanical ventilation, length of ICU stay and mortality (all $p<$

Table 2 The characteristics of included patients

\begin{tabular}{|c|c|c|c|c|}
\hline Variables & $\operatorname{LCOS} \operatorname{group}(n=35)$ & No LCOS group $(n=248)$ & $t / x^{2}$ & $P$ \\
\hline Male/female & $19 / 16$ & $136 / 112$ & 1.089 & 0.071 \\
\hline Age(y) & $3.12 \pm 2.58$ & $6.91 \pm 5.24$ & 1.124 & 0.002 \\
\hline Preoperative oxygen saturation(\%) & $91.62 \pm 10.31$ & $94.23 \pm 10.55$ & 7.033 & 0.041 \\
\hline Inner diameter of left atrium (mm) & $17.93 \pm 7.18$ & $17.17 \pm 8.41$ & 3.126 & 0.085 \\
\hline End diastolic diameter of left ventricle (mm) & $26.25 \pm 8.24$ & $27.57 \pm 7.09$ & 7.104 & 0.098 \\
\hline End systolic diameter of left ventricular (mm) & $17.43 \pm 7.11$ & $17.52 \pm 7.14$ & 4.116 & 0.102 \\
\hline Left ventricular ejection fraction (\%) & $67.41 \pm 8.33$ & $68.12 \pm 7.51$ & 10.274 & 0.117 \\
\hline Inner diameter of pulmonary artery (mm) & $21.28 \pm 9.26$ & $20.86 \pm 9.33$ & 4.201 & 0.079 \\
\hline \multicolumn{5}{|l|}{ Atrial shunt } \\
\hline Left to right shunt & $13(37.15 \%)$ & $93(37.50 \%)$ & 1.192 & 0.085 \\
\hline No shunt & $18(51.43 \%)$ & $121(48.79 \%)$ & 1.169 & 0.059 \\
\hline Right to left shunt & $2(5.71 \%)$ & $19(7.66 \%)$ & 1.202 & 0.076 \\
\hline Two-way shunt & $2(5.71 \%)$ & $15(6.05 \%)$ & 1.113 & 0.069 \\
\hline \multicolumn{5}{|l|}{ Ventricular shunt } \\
\hline Left to right shunt & $12(34.29 \%)$ & 95 (38.31\%) & 1.120 & 0.072 \\
\hline No shunt & $17(48.57 \%)$ & $124(50 \%)$ & 1.286 & 0.066 \\
\hline Right to left shunt & $2(5.71 \%)$ & $19(7.66 \%)$ & 1.113 & 0.084 \\
\hline Two-way shunt & $4(11.43 \%)$ & $10(4.03 \%)$ & 1.208 & 0.038 \\
\hline \multicolumn{5}{|l|}{ Preoperative laboratory examination } \\
\hline White blood cell count $\left(\times 10^{9} \cdot \mathrm{L}^{-1}\right)$ & $9.03 \pm 1.61$ & $8.93 \pm 1.23$ & 1.128 & 0.077 \\
\hline Platelet count $\left(\times 10^{9} \cdot \mathrm{L}^{-1}\right)$ & $213.71 \pm 84.52$ & $210.24 \pm 123.12$ & 1.246 & 0.104 \\
\hline Red blood cell count $\left(\times 10^{9} \cdot \mathrm{L}^{-1}\right)$ & $4.73 \pm 1.17$ & $4.66 \pm 1.14$ & 1.093 & 0.071 \\
\hline Creatinine $\left(\mu \mathrm{mol} \cdot \mathrm{L}^{-1}\right)$ & $34.13 \pm 14.36$ & $33.26 \pm 15.23$ & 2.146 & 0.085 \\
\hline Alanine aminotransferase $\left(U \cdot L^{-1}\right)$ & $18.27 \pm 10.12$ & $17.13 \pm 12.56$ & 3.108 & 0.063 \\
\hline Aspartate aminotransferase $\left(U \cdot L^{-1}\right)$ & $19.34 \pm 12.32$ & $19.46 \pm 15.30$ & 2.997 & 0.102 \\
\hline Duration of surgery (min) & $125.52 \pm 66.49$ & $124.59 \pm 75.17$ & 12.084 & 0.105 \\
\hline Duration of CPB (min) & $67.73 \pm 22.97$ & $51.09 \pm 23.95$ & 9.169 & 0.013 \\
\hline Infusion of red blood cell suspension (mL) & $224.36 \pm 98.14$ & $228.65 \pm 92.17$ & 18.104 & 0.098 \\
\hline Postoperative residual shunt & $4(11.43 \%)$ & $3(1.21 \%)$ & 1.297 & 0.018 \\
\hline
\end{tabular}


Table 3 The variable assignment of multivariate logistic regression

\begin{tabular}{lll}
\hline Factors & Variables & Assignment \\
\hline LCOS & $Y$ & Yes $=1$, no $=2$ \\
Age $(y)$ & $X_{1}$ & $\leq 4=1,>4=2$ \\
Preoperative oxygen saturation(\%) & $X_{2}$ & $\leq 93=1,>93=2$ \\
Two-way ventricular shunt & $X_{3}$ & Yes $=1$, no $=2$ \\
Duration of CPB (min) & $X_{4}$ & $\geq 60=1,<60=2$ \\
Postoperative residual shunt & $X_{5}$ & Yes $=1$, no $=2$ \\
\hline
\end{tabular}

$0.05)$, no significant difference in the $24 \mathrm{~h}$ drainage was found $(p=0.095)$.

\section{Discussions}

LCOS is one of the common complications after heart surgery, and it is also an important cause of death in children after CHD [11]. Studies have reported that the incidence of LCOS after heart surgery can be as high as $25.16 \%$. Although studies $[12,13]$ have reported that the occurrence of LCOS may be related to preoperative cardiac function, intraoperative operations and $\mathrm{CPB}$, there are still no exact indicators to reflect the risk of its occurrence. Therefore, exploring the risk factors of LCOS is of great significance to the prevention and treatment of LCOS after CHD in children. At present, domestic and foreign studies on the risk factors of LCOS after CHD in children are inconsistent. It is believed that the occurrence of LCOS is caused by multiple factors, including impaired systolic and diastolic function of the heart, changes in cardiac load, and activation of inflammatory transmitters $[14,15]$. The results of our study have found that age $\leq 4 \mathrm{y}$, preoperative oxygen saturation $\leq 93 \%$, two-way ventricular shunt, duration of $\mathrm{CPB} \geq 60 \mathrm{~min}$, postoperative residual shunt were the independent risk factors of LCOS in patients with CHD. Clinically, these risk factors should be identified early, and relevant intervention measures should be taken as soon as possible to reduce the occurrence of LCOS.

The younger the age, the higher the incidence of $\mathrm{L}$ COS, which may be associated to the incomplete development of myocardial cells in younger children and the susceptibility to ischemia and hypoxia $[16,17]$. At the same time, most of the younger children who require early surgery have severe disease and deformity, LCOS is more likely to occur after surgery [18]. The incidence of LCOS in children with preoperative ventricular two-way shunt was significantly higher than that of non-shunt or other shunts [19]. Ventricular horizontal bidirectional shunt mostly occurs in the late stage of left-to-right shunt CHD such as ventricular septal defect with pulmonary hypertension [20]. The possible cause of postoperative LCOS may be increased pulmonary artery pressure before surgery or increased pulmonary circulation, which may lead to increased pulmonary vascular resistance in children after surgery [21]. Meanwhile, the systemic inflammatory response caused by CPB damages the pulmonary vascular endothelium and changes the vascular inflammatory response, increases the production of thromboxane, and reduces the production of endogenous $\mathrm{NO}$, which causes pulmonary vasoconstriction and pulmonary vascular microthrombosis, leading to pulmonary blood vessels $[22,23]$. A further increase in resistance increases the right ventricular afterload, which further leads to the occurrence of right heart failure and LCOS [24].

The lung ischemia-reperfusion injury caused by $\mathrm{CPB}$ also causes damage to the alveolar epithelial-endothelial barrier, leading to pulmonary congestion and pulmonary edema, and restricting oxygenation [25]. Meanwhile, $\mathrm{CPB}$ can lead to local postoperative ischemiareperfusion injury [26]. The systemic inflammatory reaction increases the body's energy requirements, makes the body in a high metabolic state, increases myocardial oxygen consumption, increases cardiac work, and further aggravates cardiac function damage [27]. Postoperative residual shunt is a common complication after CHD surgery in children, with an incidence of 5 to $25 \%$ [24, $28,29]$. The immediate postoperative residual shunt mainly occurs in children with intracardiac malformations with severe pulmonary hypertension [30]. At the time of unidirectional valve or artificial stoma, most of these children have severe disease and poor basic cardiac function [31]. The abnormal hemodynamics caused by residual shunt can aggravate the myocardial damage [32], and finally lead to LCOS.

The complications of LCOS after CPB operation can casuse adverse consequences for the patients. This study has found that children in the LCOS group have

Table 4 Logistic regression analysis on the risk factors of LCOS in patients with CHD

\begin{tabular}{|c|c|c|c|c|c|}
\hline Variables & $\beta$ & $S^{-} x$ & OR & $95 \% \mathrm{Cl}$ & $P$ \\
\hline Age $\leq 4 y$ & 0.103 & 0.217 & 2.426 & $1.044 \sim 4.149$ & 0.012 \\
\hline Preoperative oxygen saturation $\leq 93 \%$ & 0.127 & 0.220 & 2.175 & $1.182 \sim 5.033$ & 0.025 \\
\hline Two-way ventricular shunt & 0.131 & 0.127 & 3.994 & $1.247 \sim 6.797$ & 0.006 \\
\hline Duration of $C P B \geq 60 \mathrm{~min}$ & 0.146 & 0.170 & 2.172 & $1.002 \sim 4.309$ & 0.043 \\
\hline Postoperative residual shunt & 0.109 & 0.113 & 1.487 & $1.093 \sim 2.383$ & 0.027 \\
\hline
\end{tabular}


Table 5 The postoperative complications and prognosis of patients with CHD

\begin{tabular}{|c|c|c|c|c|}
\hline Variables & $\operatorname{LCOS} \operatorname{group}(n=35)$ & No LCOS group $(n=248)$ & $t / x^{2}$ & $P$ \\
\hline $24 \mathrm{~h}$ drainage $(\mathrm{mL})$ & $136.63 \pm 53.98$ & $128.04 \pm 52.04$ & 22.107 & 0.095 \\
\hline Acute liver injury & $3(8.57 \%)$ & $7(2.82 \%)$ & 1.214 & 0.019 \\
\hline Acute kidney injury & $6(17.14 \%)$ & $9(3.63 \%)$ & 1.082 & 0.006 \\
\hline Pulmonary infection & $3(8.57 \%)$ & $6(1.72 \%)$ & 1.079 & 0.012 \\
\hline Tracheotomy & $5(14.29 \%)$ & $2(0.81 \%)$ & 1.128 & 0.001 \\
\hline Duration of mechanical ventilation(h) & $32.13 \pm 23.28$ & $10.28 \pm 7.84$ & 7.202 & 0.027 \\
\hline Duration of ICU stay(d) & $8.10 \pm 3.15$ & $3.07 \pm 2.55$ & 2.409 & 0.018 \\
\hline Mortality & $4(11.43 \%)$ & $2(0.81 \%)$ & 1.128 & 0.001 \\
\hline
\end{tabular}

increased postoperative complications and increased mortality. The possible reasons may be related to following reasons: LCOS causes the insufficient perfusion of important organs such as liver, kidney, brain, leading to function damage [33]. The pulmonary circulatory congestion caused by LCOS causes pulmonary interstitial edema, affects the blood oxygen exchange of the lungs, and increases the incidence of pulmonary complications [34]. At present, there is a consensus that LCOS after open heart surgery is a risk factor for poor prognosis after cardiovascular disease [35]. Therefore, through strict monitoring of various indicators of cardiac output, early diagnosis of LCOS, and timely search for the cause and treatment, the effects of reducing complications and improving prognosis can be achieved [36]. Clinically, the timing of surgery should be strictly controlled according to the actual conditions of the child's disease, age, etc. Before surgery, heart failure should be actively controlled and pulmonary artery pressure should be lowered [37]. During surgery, fine operations should be performed to reduce residual shunts and secondary operations. At the same time, surgical techniques should be continuously improved, surgical methods should be improved, and the aortic occlusion time should be shortened as much as possible [38]. Besides, it is necessary to improve the perioperative management and the recognition of LCOS, early detection and treatment are warranted.

This study has certain clinical significance for identifying the risk factors of postoperative LCOS in children with CHD and provides reference value for the prevention of LCOS. However, this study has certain limitations. This study is a single-center retrospective analysis with a small sample size, it is difficult to classify and compare the specific type of CHD. Therefore, it is necessary to design a rigorous multi-center prospective studies for better identifying the risk factors of LCOS, to provide insights into the clinical management of $\mathrm{CHD}$.

\section{Conclusions}

In conclusion, the incidence of LCOS after CHD is high and it's closely associated with the prognosis of $\mathrm{CHD}$ patients. For
CHD patients with age $\leq 4 y$, preoperative oxygen saturation $\leq$ $93 \%$, two-way ventricular shunt, duration of $\mathrm{CPB} \geq 60 \mathrm{~min}$, postoperative residual shunt, they may have higher risk of LCOS. Those risk factors should be early identified and intervened to reduce the onset of LCOS. Limited by sample size, future studies with larger sample size in difference areas are warranted to further elucidate the risk factors of LCOS, to provide reliable evidences to the management of $\mathrm{CHD}$.

\section{Abbreviations \\ LCOS: Low cardiac output syndrome; CHD: Congenital heart disease; CPB: Cardiopulmonary bypass}

\section{Acknowledgments}

None.

Authors' contributions

B S, R D designed research; B S, H D, R D conducted research; B S, R D analyzed data; R D wrote the first draft of manuscript; R D had primary responsibility for final content. All authors read and approved the final manuscript.

\section{Funding}

None.

\section{Availability of data and materials}

All data generated or analyzed during this study are included in this published article.

\section{Declarations}

Ethics approval and consent to participate

In this study, all methods were performed in accordance with the relevant guidelines and regulations. Our study had been approved by the ethics committee of our hospital (XC201811029a), and written informed consents had been obtained from the relatives or guardians of the included CHD children.

Consent for publication

Not applicable.

\section{Competing interests}

The authors declare that they have no competing interests.

Received: 6 March 2021 Accepted: 7 May 2021

Published online: 17 May 2021

References

1. Le Bloa M, Abadir S, Nair K, Mondesert B, Khairy P. New developments in catheter ablation for patients with congenital heart disease. Expert Rev Cardiovasc Ther. 2021;19(1):15-26. https://doi.org/10.1080/14779072.2021.1 847082. 
2. Egbe AC, Vojjini R, Badawy M, Jain V, Bonnichsen CR, Reddy YNV, et al. Heightened dependence of left-heart filling pressures on right-heart failure in congenital heart disease. Can J Cardiol. 2021;37(1):131-9. https://doi.org/1 0.1016/j.cjca.2020.02.084.

3. Huisenga D, La Bastide-Van Gemert S, Van Bergen A, Sweeney J, HaddersAlgra M. Developmental outcomes after early surgery for complex congenital heart disease: a systematic review and meta-analysis. Dev Med Child Neurol. 2021;63(1):29-46. https://doi.org/10.1111/dmcn.14512.

4. Baumgartner H, De Backer J, Babu-Narayan SV, Budts W, Chessa M, Diller GP, et al. 2020 ESC guidelines for the management of adult congenital heart disease. Eur Heart J. 2021;42(6):563-645. https:/doi.org/10.1093/eurheartj/ehaa554.

5. Karsenty C, Khraiche D, Jais JP, Raimondi F, Ladouceur M, Waldmann V, et al. Predictors of low exercise cardiac output in patients with severe pulmonic regurgitation. Heart. 2021;107(3):223-8. https:/doi.org/10.1136/heartjnl-2020-317550.

6. Marwali EM, Caesa P, Rayhan M, Roebiono PS, Fakhri D, Haas NA, et al. The effect of oral triiodothyronine supplementation on lactate and pyruvate after paediatric cardiac surgery. Cardiol Young. 2021;31(2):205-11. https:// doi.org/10.1017/S1047951120003698.

7. Miike $H$, Ohuchi $H$, Hayama $Y$, Isawa $T$, Sakaguchi H, Kurosaki K, et al. Systemic artery vasoconstrictor therapy in Fontan patients with high cardiac output-heart failure: a single-center experience. Pediatr Cardiol. 2021;42(3): 700-6. https://doi.org/10.1007/s00246-020-02532-7.

8. Jain PN, Robertson M, Lasa JJ, Shekerdemian L, Guffey D, Zhang Y, et al. Altered metabolic and inflammatory transcriptomics after cardiac surgery in neonates with congenital heart disease. Sci Rep. 2021;11(1):4965. https://doi. org/10.1038/s41598-021-83882-X.

9. Chandler HK, Kirsch R. Management of the low cardiac output syndrome following surgery for congenital heart disease. Curr Cardiol Rev. 2016;12(2): 107-11. https://doi.org/10.2174/1573403X12666151119164647.

10. Lomivorotov W, Efremov SM, Kirov MY, Fominskiy EV, Karaskov AM. Lowcardiac-output syndrome after cardiac surgery. J Cardiothorac Vasc Anesth. 2017;31(1):291-308. https://doi.org/10.1053/j.jvca.2016.05.029.

11. Masse L, Antonacci M. Low cardiac output syndrome: identification and management. Crit Care Nurs Clin North Am. 2005;17(4):375-83, x. https:// doi.org/10.1016/j.ccell.2005.07.005.

12. Epting CL, McBride ME, Wald EL, Costello JM. Pathophysiology of postoperative low cardiac output syndrome. Curr Vasc Pharmacol. 2016;14(1): 14-23. https://doi.org/10.2174/1570161113666151014123718.

13. Nordness MJ, Westrick AC, Chen H, Clay MA. Identification of low cardiac output syndrome at the bedside: a pediatric cardiac intensive care unit survey. Crit Care Nurse. 2019;39(2):e1-7. https://doi.org/10.4037/ccn2019794.

14. Ulate KP, Yanay O, Jeffries H, Baden H, Di Gennaro JL, Zimmerman J. An elevated low cardiac output syndrome score is associated with morbidity in infants after congenital heart surgery. Pediatr Crit Care Med. 2017;18(1):2633. https://doi.org/10.1097/PCC.0000000000000979.

15. Rogers L, Ray S, Johnson M, Feinstein Y, Dominguez TE, Peters MJ, et al. The inadequate oxygen delivery index and low cardiac output syndrome score as predictors of adverse events associated with low cardiac output syndrome early after cardiac bypass. Pediatr Crit Care Med. 2019;20(8):73743. https://doi.org/10.1097/PCC.0000000000001960.

16. Guerrero Orriach JL, Navarro Arce I, Hernandez Rodriguez P, Raigon Ponferrada A, Malo Manso A, Ramirez Aliaga M, et al. Preservation of renal function in cardiac surgery patients with low cardiac output syndrome: levosimendan vs beta agonists. BMC Anesthesiol. 2019;19(1):212. https://doi.org/10.1186/s12871-019-0888-2.

17. Du X, Chen H, Song X, Wang S, Hao Z, Yin L, et al. Risk factors for low cardiac output syndrome in children with congenital heart disease undergoing cardiac surgery: a retrospective cohort study. BMC Pediatr. 2020;20(1):87. https://doi.org/10.1186/s12887-020-1972-y.

18. Nair AG, Sleeper LA, Smoot LB, Wigmore D, Mecklosky J, Andren K, et al. Extracorporeal membrane oxygenation support after heart transplantation in children-outcomes of a single center cohort. Pediatr Crit Care Med. 2020; 21(4):332-9. https://doi.org/10.1097/PCC.0000000000002192

19. Ricci Z, Cecconi G, Lillo R, Di Chiara L, Toscano A, lacobelli R. Cardiac output measurement with echocardiography and pressure recording analytical method in pediatric patients admitted to the cardiac intensive care unit: a retrospective assessment of Bias between the two methods. J Cardiothorac Vasc Anesth. 2020;18(2):10-9.

20. Amabili P, Benbouchta $S$, Roediger $L$, Senard M, Hubert MB, Donneau AF, et al. Low cardiac output syndrome after adult cardiac surgery: predictive value of peak systolic global longitudinal strain. Anesth Analg. 2018;126(5): 1476-83. https://doi.org/10.1213/ANE.0000000000002605.
21. Ding W, Ji Q, Shi Y, Ma R. Predictors of low cardiac output syndrome after isolated coronary artery bypass grafting. Int Heart J. 2015;56(2):144-9. https://doi.org/10.1536/ihj.14-231.

22. Balderas-Munoz K, Rodriguez-Zanella H, Fritche-Salazar JF, Avila-Vanzzini N, Juarez Orozco LE, Arias-Godinez JA, et al. Improving risk assessment for postsurgical low cardiac output syndrome in patients without severely reduced ejection fraction undergoing open aortic valve replacement. The role of global longitudinal strain and right ventricular free wall strain. Int J Cardiovasc Imaging. 2017;33(10):1483-9. https://doi.org/10.1007/s10554-017-1139-6.

23. Burkhardt BE, Rucker G, Stiller B. Prophylactic milrinone for the prevention of low cardiac output syndrome and mortality in children undergoing surgery for congenital heart disease. Cochrane Database Syst Rev. 2015;3:CD009515.

24. Hummel J, Rucker G, Stiller B. Prophylactic levosimendan for the prevention of low cardiac output syndrome and mortality in paediatric patients undergoing surgery for congenital heart disease. Cochrane Database Syst Rev. 2017;8:CD011312

25. Wang H, Luo Q, Li Y, Zhang L, Wu X, Yan F. Effect of prophylactic Levosimendan on all-cause mortality in pediatric patients undergoing cardiac surgery-an updated systematic review and meta-analysis. Front Pediatr. 2020;8:456. https://doi.org/10.3389/fped.2020.00456.

26. Avila-Alvarez A, Del Cerro Marin MJ, Bautista-Hernandez V. Pulmonary vasodilators in the Management of low Cardiac Output Syndrome after Pediatric Cardiac Surgery. Curr Vasc Pharmacol. 2016;14(1):37-47. https://doi. org/10.2174/1570161113666151014124912.

27. Liu H, Zheng SQ, Li XY, Zeng ZH, Zhong JS, Chen JQ, et al. Derivation and validation of a Nomogram to predict in-hospital complications in children with tetralogy of Fallot repaired at an older age. J Am Heart Assoc. 2019; 8(21):e013388. https://doi.org/10.1161/JAHA.119.013388.

28. Hoffman TM, Wernovsky G, Atz AM, Kulik TJ, Nelson DP, Chang AC, et al. Efficacy and safety of milrinone in preventing low cardiac output syndrome in infants and children after corrective surgery for congenital heart disease. Circulation. 2003;107(7): 996-1002. https:/doi.org/10.1161/01.CIR.0000051365.81920.28.

29. Perez-Navero JL, Merino-Cejas C, Ibarra de la Rosa I, Jaraba-Caballero S, Frias-Perez M, Gomez-Guzman E, et al. Evaluation of the vasoactive-inotropic score, mid-regional pro-adrenomedullin and cardiac troponin I as predictors of low cardiac output syndrome in children after congenital heart disease surgery. Med Int. 2019;43(6):329-36.

30. Hickok RL, Spaeder MC, Berger J, Schuette JJ, Klugman D. Postoperative abdominal NIRS values predict low cardiac output syndrome in neonates. World J Pediatr Congenit Heart Surg. 2016;7(2):180-4. https://doi.org/10.1177/2150135115618939.

31. Wald RM, Silversides CK, Kingdom J, Toi A, Lau CS, Mason J, et al. Maternal cardiac output and fetal doppler predict adverse neonatal outcomes in pregnant women with heart disease. J Am Heart Assoc. 2015;4(11):1-13.

32. Kopf GS, Mello DM. Surgery for congenital heart disease in low-birth weight neonates: a comprehensive statewide Connecticut program to improve outcomes. Conn Med. 2003:67(6):327-32.

33. Bhalala US, Nishisaki A, McQueen D, Bird GL, Morrison WE, Nadkarni VM, et al. Change in regional (somatic) near-infrared spectroscopy is not a useful indicator of clinically detectable low cardiac output in children after surgery for congenital heart defects. Pediatr Crit Care Med. 2012;13(5):529-34. https://doi.org/10.1097/PCC.0b013e3182389531.

34. Maganti M, Badiwala M, Sheikh A, Scully H, Feindel C, David TE, et al. Predictors of low cardiac output syndrome after isolated mitral valve surgery. J Thorac Cardiovasc Surg. 2010;140(4):790-6. https://doi.org/10.1016/j.jtcvs.2009.11.022.

35. Bautista-Hernandez V, Karamanlidis G, McCully JD, Del Nido PJ. Cellular and molecular mechanisms of low cardiac output syndrome after pediatric cardiac surgery. Curr Vasc Pharmacol. 2016;14(1):5-13. https://doi.org/10.21 74/1570161113666151014122557

36. Rao V, Ivanov J, Weisel RD, Ikonomidis JS, Christakis GT, David TE. Predictors of low cardiac output syndrome after coronary artery bypass. J Thorac Cardiovasc Surg. 1996;112(1):38-51. https://doi.org/10.1016/S0022-5223(96)70176-9.

37. Bari V, Vaini E, Pistuddi V, Fantinato A, Cairo B, De Maria B, et al. Short-term multiscale complexity analysis of cardiovascular variability improves low cardiac output syndrome risk stratification after coronary artery bypass grafting Physiol Meas. 2019;40(4):044001. https://doi.org/10.1088/1361-6579/ab12f0.

38. Cuadrado AR. Management of postoperative low cardiac output syndrome. Crit Care Nurs Q. 2002;25(3):63-71. https:/doi.org/10.1097/00002727-200211000-00008.

\section{Publisher's Note}

Springer Nature remains neutral with regard to jurisdictional claims in published maps and institutional affiliations. 